University of South Florida

DIGITAL COMMONS

Digital Commons @ University of

@ UNIVERSITY OF SOUTH FLORIDA

South Florida

\title{
Using pedestrian choice research to facilitate resource engagement in a midsized academic library.
}

\author{
Kaya van Beynen \\ University of South Florida St. Petersburg, kayatown@usf.edu \\ Patricia C. Pettijohn \\ University of South Florida St. Petersburg \\ Marcy Carrel
}

Follow this and additional works at: https://digitalcommons.usf.edu/fac_publications

Part of the Library and Information Science Commons

\section{Recommended Citation}

van Beynen, K., Pettijohn, P.C. \& Carrel, M. (2010) Using pedestrian choice research to facilitate resource engagement in a midsized academic library. Journal of Academic Librarianship, 36(5), 412-419.

doi:10.1016/j.acalib.2010.06.005

This Article is brought to you for free and open access by the USF Faculty Publications at Digital Commons @ University of South Florida. It has been accepted for inclusion in USF St. Petersburg campus Faculty Publications by an authorized administrator of Digital Commons @ University of South Florida. For more information, please contact digitalcommons@usf.edu. 
Keywords: Pedestrian Choice, Academic Library, Engagement. p1

\title{
Article Title:
}

Using Pedestrian Choice Research to Facilitate Resource Engagement in a Midsized Academic Library

\section{Authors:}

1. Kaya van Beynen, M.Sc., M.A., Reference and Instruction Librarian*

2. Patricia Pettijohn, MLIS, Head, Collection Development and Technical Services

3. Marcy Carrel, MBA, MLIS, Reference and Instruction Librarian

Nelson Poynter Memorial Library

University of South Florida, St. Petersburg

140 7th Ave. S, St. Petersburg, FL 33701

*Phone: 727-873-4626; Email: kayatown@ nelson.usf.edu

\begin{abstract}
:
For a one year period, visitors to the Nelson Poynter Memorial Library, University of South Florida St. Petersburg were observed regarding how they negotiated through the first floor and interacted with the library resources and educational displays. Pedestrian choice research was applied to the library to better understand visitor movement and facilitate greater interaction and engagement. To encourage greater interaction, future library design needs to strategize the high demand services and resources along the natural pathways and to the immediate library entrance, while remote locations should be redesigned as desirable destinations that provide high benefits to students and library visitors.
\end{abstract}


Keywords: Pedestrian Choice, Academic Library, Engagement. p2

\section{Introduction:}

With less space needed for print reference, periodical, and microfiche collections, prime library space needs to be redesigned as a destination that seamlessly blends student and faculty services, resources, learning, and social interaction. Building design and environment can significantly increase visitor use of the library based on measures of exit counts, circulation statistics, reference interactions, and in-house use. For a one year period, visitors to the Nelson Poynter Memorial Library, University of South Florida St. Petersburg were observed regarding how they negotiated through the first floor and interacted with the library resources and educational displays. Pedestrian choice research was adapted and applied to the physical space of the academic library in order to better understand visitor movement and facilitate greater interaction and engagement with our physical and educational environment. The majority of library visitors settled in the immediate vicinity of the library entrance, while visitors with a clear purpose traversed to more remote destinations. Visitors that moved beyond the computer commons, tended to engage in greater amounts of browsing and reading of library displays and materials. Thus to encourage greater interaction, future library design needs to strategize the high demand services and resources along the natural pathways and to the immediate library entrance, while remote locations should be redesigned as desirable destinations that provide high benefits to students and library visitors.

\section{Institutional Context}

The University of South Florida St. Petersburg has experienced substantial growth in the past five years evolving from a regional campus embedded in a university system, to a separately accredited institution within that system. This evolution is unusual in that USF St. Petersburg 
Keywords: Pedestrian Choice, Academic Library, Engagement. p3

(USFSP) was originally conceived as an institution offering upper-level undergraduate and graduate programs. Lower-level undergraduates began to be admitted to USFSP in 2004 and two years later, the on-campus residential dorm opened. From 2004 to 2008, the number of applications for admission has increased by almost $44 \%$, while the number of students has increased by $18 \%$. Overall, the number of student credit hours taught, academic programs offered, and number of faculty have all increased. For the 2008-09 academic year, USF St. Petersburg served a total of 3,500 undergraduate and graduate students who were enrolled in almost 40 degree programs.

Built in 1996, the Nelson Poynter Memorial Library serves the University of South Florida St. Petersburg. The southern side of the library boasts views of Tampa Bay, a private marina, a city park, and the Salvador Dali Museum. The most prominent architectural feature of the library interior is the large atrium when visitors first enter the building. The library's three floors total 80,000 square feet, of which 54,000 is usable space. At the outset of our research, approximately 230,000 books \& media were located on the second and third floors, while the print reference, periodical, and microfilm/fiche collections were located on the first floor. In contrast to the growth experienced by the university, the library's statistics are mixed. Reference interactions, bibliographic instruction classes, and circulation totals have increased, while the door count and inter-library loan services have decreased. Additionally, until the completion of a planned new student center, the library serves as the center of campus life.

\section{Libraries as Place}


Keywords: Pedestrian Choice, Academic Library, Engagement. p4

Traditionally, academic libraries were designed as places to collect, preserve and secure print collections $^{1}$. Their interiors were frequently dimly lit, difficult to navigate, and prime real estate was given to services that did not directly interact with library visitors. Assessments of library space frequently focused on libraries as containers or repositories of information, utilizing formulas that combine measures of volumes held, student FTE, library square footage, seating and shelving requirements, along with wiring and network capacity. ${ }^{2,3,4}$ This traditional concept of academic libraries is increasingly being reevaluated and supplanted by the notion of libraries as destinations that seamlessly blend services, resources, learning, and social interaction. ${ }^{5}$

Research exploring user perception of library space has been dominated by the use of survey instruments measuring user attitudes toward the physical building, including LibQual, ${ }^{6}$ the prominent annual assessment tool produced by the Association of Research Libraries, and Rodski, a library survey widely used in Australia. Indeed, LibQual includes "Library as Place" as one of three core dimensions of library service assessed. In a survey of academic library construction and design projects, Shill \& Tonner $^{7}$ note that more than 400 major academic library construction projects (new library buildings, additions, and renovations) were completed in the United States between 1995 and 2002. In a companion article comparing before and after usage patterns in these newly built and renovated libraries, Shill and Tonner $^{8}$ found that a high quality building and environment can significantly increase visitor use of the library based on measures of exit counts, circulation statistics, reference interactions, and in-house use. Design features that contributed to increased usage were overall library ambiance, effective layout, natural lighting, seating quality, telecommunications infrastructure, and presence of an 
Keywords: Pedestrian Choice, Academic Library, Engagement. p5

instruction lab. More recently, Bennett ${ }^{9}$ argued that the goal of library space design should focus on collaborative learning and the social context of learning.

Qualitative and ethnographic techniques are increasingly applied to understand this broader notion of library as a place for social interaction and collaborative learning. Using unobtrusive observation, storyboarding, and stakeholder interviews, the MAYA design group explored user experiences in a large public library environment. ${ }^{10}$ User-centered design techniques were used to create textual narratives and visual storyboards that represented the library patron experience of the library, allowing library managers to empathize with users. Although public response to this redesign project has been widely discussed in the popular and academic press, ${ }^{11,12,13}$, discussions of the proprietary methodology and research design is limited. Given and Leckie ${ }^{14}$ used a "seating sweeps" approach to analyze how libraries function as unique public spaces. This approach, common to marketing research, captured a snapshot of the demographic, activity, location, and personal belongings of library users. Although unobtrusive observation was utilized in this approach, library patron movement and pedestrian choices were not addressed.

In a groundbreaking study of undergraduate research conducted at the University of Rochester, library anthropologist Foster ${ }^{15}$ and colleagues utilized a number of ethnographic approaches, including asking students to create their own designs of ideal library spaces. Another usercentered approach involved videotaping student interviews, then utilizing the video interviews for co-viewing and brainstorming sessions with library staff. Student participants created photosurveys and mapping diaries to capture their real time study habits across campus environments. While this research directly explored the use of library space by students using a number of 
ethnographic techniques, including observation, the goal of the research was to explore how undergraduates write research papers, not how they conduct library research, or navigate the library environment. Even as librarians are increasingly utilizing qualitative methodologies to better understand the student research process and how students occupy library space, ethnographic research to assess pedestrian choices within libraries has not occurred, providing little scientific measurement of what elements facilitate visitor engagement with library services and resources.

\section{Pedestrian Choice Research}

Pedestrian choice research is a popular methodology to assess visitor engagement in public spaces such as museum exhibits. ${ }^{16,17}$ The goal of this research is to utilize an interactive approach that considers both the visitor and the exhibit. Factors affecting the visitor experience can be the visitors' agenda, interests, and prior knowledge. Other factors that influence the experience are more spatially oriented such as the architectural space and exhibit design. By adapting the knowledge produced through museum studies to the library, both visitors and space are considered, allowing libraries to more fully design a spatial environment that encourages and enables visitor interaction and student learning.

According to the general value principle, visitors to public spaces unconsciously weigh perceived or actual costs against perceived benefits to guide their interaction and movement choices. ${ }^{18}$ These costs may include the time or effort required to engage in an activity or to better view an exhibit. Benefits might include increased knowledge, satisfaction, enjoyment, positive social interaction, and greater efficiency. In general, individuals have little control over 
possible benefits, and greater control over decreasing costs. Hence, the value of an experience may increase even if the benefits remain constant while the associative costs decline. ${ }^{19}$

The economy of movement principle ${ }^{20}$ similarly models patterns of movement in public spaces according to the visitors' costs and benefits. Pedestrian choice studies in the United States frequently note the tendency of people to walk on the right and to turn right when confronted with a choice or an intersection. This rightward tendency is credited to people's unconscious desire to reduce their effort (limiting the number of steps), in order to maximize their benefits. Visitors will rarely backtrack to view an object as this requires additional costs from a greater exertion of effort. A subsequent review by Bitgood and Dukes ${ }^{21}$ found that the location of landmark attractions and the orientation of established pathways wielded a greater force on pedestrian choices. Thus visitors intuitively factor in their level of exertion as they make their choice of destination and engagement.

The identification and application of these principles are key to our understanding of the library's built environment. When confronted with these theories, libraries can either increase the benefits from leftward destinations by increasing their value, or design a space that effectively reduces visitor costs by situating displays and services along the visitors' natural pathways. Thus, it is imperative for libraries to know how visitors circulate through their library as this can affect what they perceive, learn, and experience about the library's resources and services.

\section{Methodology:}


Keywords: Pedestrian Choice, Academic Library, Engagement. p8

The methodology for this study involved direct observation of visitors to a mid-sized academic library. For three semesters during 2007 and 2008, random samples of visitors were observed as they used the first floor of the Nelson Poynter Memorial Library at the University of South Florida St. Petersburg. Researchers were equipped with a map of the library's first floor with all the various attributes, facilities, and resources numerically identified, a list of possible visitor activities, space to track visitor stops, and a section for comments. For each observation, the researcher noted the visitor's stopping location (computers, reference desk, new books shelf, etc.) and the corresponding activity (reading, using, socializing, asking for help) done at that specific location. Visitors were observed from the time they entered the library until they a) settled at their intended destination; b) left the library; c) left the first floor; or d) five minutes of observation had lapsed.

\section{Insert Illustration 1: Map and Tracking Guide for the Library's $1^{\text {st }}$ floor}

During each phase of the observations, a number of changes were made to the library environment. During the second observation, the media collection was moved from the second floor to a prominent location on the first floor, a modular mobile display was moved to the middle of the library's atrium, and a "new books" section was added near the library entrance/exit. The changes were equally dramatic for the third observation. A new laptop bistro bar was created along a bank of windows on the first floor and the current periodical shelves swapped locations with a group of tables and chairs, creating a more open use space just north (and to the right) of the entrance. These changes were remapped on the observation instrument. 
Keywords: Pedestrian Choice, Academic Library, Engagement. p9

A total of 603 library visitors were observed across all three sessions, representing $7 \%$ of the total library visitors during the observation weeks.

Each observation period was followed by a focus group session where students were asked about building use, barriers to use, and their ideas about library design. Specifically, focus group participants were asked:

- What do you like about the current layout of the first floor of the Nelson Poynter Library?

- What would you like to change about the current layout of the first floor?

- What kinds of activities do you currently do in the library?

- What kinds of activities would you like to do in the library?

- And what kind of space/furniture/or layout would you need to do this?

A total of 22 students participated in the three focus groups.

Observations were recorded on a combined map and data collection form, which provided a visual representation of the visitors' pathways and number codes for each unique location within the library. The observers traced the pathways of the visitors to ascertain how they moved through the space and around objects and to test the leftward theory. Comments were also recorded for any unusual or noteworthy activity or event (i.e. student "walking and circling library with giant stuffed Chik-Fil-A cow"). Location and activity data from these observations were then entered into an Excel spreadsheet to facilitate data analysis. Data items recorded include: date, time, gender, individual/group, number of stops, activity at first stop, and location code for each stop during the designated observation time period. Data were cleaned by removing any incomplete observations. Because changes were made to the library layout and 
library maps between the three observation sessions, universal codes were created to indicate locations whose map codes may have changed between sessions.

Summary statistics were then calculated for all observation sessions and for each of the three sessions individually. The most frequent first stops for each observation session and for all three observation sessions as a whole were calculated and compared. These most frequent first stops were analyzed by gender and by the individual versus group characteristic. Frequencies for all stops were also examined, as well as the sequences between first and second stops, and the activities conducted at the stops. Data analysis was conducted using Excel PivotTables and charts were created to both facilitate analysis and highlight findings.

\section{Results - Observations}

The six most frequent first stops, across the total of all sessions, were as follows: computer commons (172 stops or $28.5 \%$ ); stairs (60 stops or $10.0 \%$ ); circulation (58 stops or $9.6 \%$ ); restrooms (43 stops or 7.1\%); reference (39 stops or 6.5\%); and current periodicals (26 stops or 4.3\%). The computer commons ranked highest (most frequent first stop) across all observation sessions; circulation and reference were consistently in the top five stops. Of the 603 observations, 274 visitors (45.4\%) made one stop only; 246 visitors (40.8\%) made two or three stops, and 83 visitors (13.8\%) made four or more stops. Across all observation sessions, there were no significant gender differences with regard to first stops or total number of stops made. For both individuals versus group visitors, the top five first stops were the same, although in varying order: individuals were more likely than groups to first visit the stairs (11\% versus 7\%) and the restrooms ( $8 \%$ versus $4 \%$ ). 
Keywords: Pedestrian Choice, Academic Library, Engagement. p11

As the most frequent first stop, the computer commons was also the first and final destination for 132 or $21.9 \%$ of all visitors across all observation sessions. In other words, for those visitors whose first stop was the computer commons, a full 76.7\% (132 of 172) made this stop their final destination. The staircase leading to the second and third floors was also a popular initial destination. Across all observation sessions, 60 visitors (10.0\%) headed directly to the staircase as their first stop and, not surprisingly, 56 or $93.3 \%$ of these visitors made no other stops during the five minute observation period (researchers did not follow visitors beyond the first floor). For the other popular first stops, visitor movements vary considerably. About half, or 32 of the 58 visitors who stopped first at circulation, made no other stops during the observation time. In other words, about half of these visitors remained at the circulation desk for over five minutes, while the other half either exited or moved on to other locations in the library. A total of 39 visitors $(6.5 \%)$ stopped first at the reference desk and of these, only three remained at the desk beyond the five minute observation time. Of the 26 visitors whose first stop was the current periodicals, none remained at that stop for more than the designated five minute observation time.

Across the three observation cycles, the 603 visitors to the library made a total of 1,280 stops. The average and median number of stops is two; the range is one to eight stops. The computer commons was the most frequent first stop (172 of 603), as well as the most frequented stop overall (250 of 1280). However, if first stops are excluded, circulation becomes the most frequent stop (105 of 677), followed by the computer commons (78 stops), current periodicals (62 stops), reference desk (58 stops), and new books cart (47 stops). As such, the visitors that 
Keywords: Pedestrian Choice, Academic Library, Engagement. p12

move past their $1^{\text {st }}$ stop tend to engage with library services and resource displays in a greater degree. These changes can be seen in Illustration 2 .

\section{Insert Illustration 2: Circle Proportion Map of the Location and Number of Stops}

The most frequently observed activity was using an item at that stop such as the computer, printer, etc. A total of 551 or $42.9 \%$ of all stops across all observations sessions were recorded as using, followed by browsing (looking but not touching) at 318 or $24.8 \%$; and asking for help (i.e. at the reference or circulation desk) at 211 or $16.4 \%$. Socializing and asking for help activities, as a percentage of all activities, varied only slightly over the three observation sessions. Laptop use fluctuated over the three observations sessions, yet never totaled more than $3.4 \%$ (second session) of all activities. Browsing and reading (combined) increased over the observation periods from $22.9 \%$ in the first session, to $29.4 \%$ in the second, and $31.9 \%$ in the third observation session.

As the majority of visitors (520 or $86.2 \%$ ) settled in their desired location within three or fewer stops, we separated out the subset of 83 visitors who made four or more stops for closer examination of their stopping locations, movement patterns, and associated activities. These visitors were nearly equally divided by gender (42 females and 41 males). For session one, $11.6 \%$ of visitors made four or more stops; for session two, $16.4 \%$ of visitors, and for session three, $13.5 \%$ of visitors. Visitors with four or more stops were more likely to engage in reading or browsing activities than visitors with one to three stops: $74.7 \%$ (62 of 83 ) versus $21.5 \%$ (112 of 520 visitors). While browsing or reading activities comprised 20.5\% (176) of all 860 stops 
Keywords: Pedestrian Choice, Academic Library, Engagement. p13

made by visitors with three or fewer stops, browsing or reading activities comprised $44.7 \%$ (189) of all 432 stops made by visitors with four or more stops. Finally, although the 83 visitors making four or more stops represent only $13.8 \%$ of all visitors, they accounted for $53.7 \%$ of all 318 browsing stops and $38.3 \%$ of all 47 reading stops.

\section{Results - Focus Groups}

Students reported that they found the library to be a good central place on campus to meet people and that the library atrium provided easy visibility to see people as they entered or exited the library. With regard to the various library displays, participants in the first focus group commented on their "tunnel vision" and failure to notice either the information monitor or book displays located along the circumference of the atrium.

By the second focus group - following relocation of the new books cart, expanded atrium display, and the introduction of an updated information monitor with a larger flat panel screen students responded positively to library displays. They reported observing the displays and enjoyed walking around the exhibits and looking at the books. Overall, students expressed greatest interest in exhibits about social issues, local topics and events, or world events that helped raise their awareness of social issues or broader events in society. However, students in the second focus group were hesitant to touch the display books. They thought the presentation looked "too nice" and that the books were placed there strictly for show. In response, we added bright signs saying "Check Me Out" to diminish resistance to touching the books on display.

During both the first and second focus groups, students demanded more electrical outlets for their laptops, specifically requesting these outlets be located by windows and areas with natural 
light. During the third focus group, the need for further electrical outlets was not mentioned as an issue by the students. While this could be due to the different characteristics of the third focus group participants, we believe that the new laptop bistro has resolved the connectivity issue for now - as students have an obvious place to plug in their laptops.

In each of the focus groups, participants liked the idea of library events, such as lectures, book or poetry readings. Science or current events talks were particularly popular. We received mixed reviews regarding music in the library; some students were excited, others didn't want the distraction. The students liked the sunny and isolated spaces where they could spread out and escape. They liked short lectures, lots of signage, and they described the best time for library events to be late afternoons.

\section{Discussion}

The applicability of the Economy of Movement Principle needs refinement in the context of the library environment. In the open environment of our library atrium, visitors predominantly remained in the immediate 400 feet (or approximately 120 meters) from the library entrance. Most sites with the highest stop counts (the computer commons, the circulation desk, the reference desk, the new books cart, and current periodicals) are within this initial domain. It is only when visitors have a specific destination (such as restrooms, remote study tables, or the stairs to the second and third floors), that they venture beyond this initial domain. Thus, the convenience and proximity of locations to the library entrance, or the desirability of landmark destinations at a greater distance, is a dominant force determining visitor stopping location, rather than a decision resulting from a rightward turning bias. 
Keywords: Pedestrian Choice, Academic Library, Engagement. p15

The application of the General Value Principle to our library redesign was successful. According to the focus group results, the students did not notice displays or library information unless these items were placed directly along their pathway. From the observation data, visitor browsing steadily increased over the three observation sessions - from $20.3 \%$ of all activities in the first observation, to $22.8 \%$ in the second observation, and $29.6 \%$ in the third observation. Visitor reading dramatically increased but not in such a linear fashion - from $6.6 \%$ of all activities in the first observation, to $2.3 \%$ of activities in the second observation, to $4.3 \%$ of activities during the third observation. It should be noted that the second cycle of observation was conducted at a time when many midterm examinations and research papers were due, thus the dramatic increase in observed reading is not unexpected. However, the overall trend across all three observations is an increase in both visitor browsing and reading.

Strategically located new stops in the library also received increased attention over the three observation sessions. Neither the new books cart nor the atrium display existed during the first observation session. By the second observation session, the new books cart accounted for $6.3 \%$ of all visitor stops and the atrium display accounted for $2.4 \%$ of all stops. By the third session, the new books cart accounted for an increased $7.9 \%$ of all stops and the atrium display visits remained fairly constant at $2.4 \%$ of all stops.

The implications of these research findings are twofold: 1) for future redesign, the library needs to strategize what services and resources should be located in the immediate library entrance in order to reduce visitor "costs" and thereby encourage greater interaction; and 2) the library 
should increase visitor "benefits" by re-designing "costly" far-flung areas of the library as desirable destinations for students.

Possible means of reducing the costs of visitor movement include having displays at easy browsing height and knowing the natural pathways. One obvious natural pathway that we have at the Nelson Poynter Library is along the right edge of the atrium space. Visitors walk along this to reach the stairs, elevators, or to go to the restrooms. Most visitors specifically walked along this right edge rather than through it or along the left edge. As such we have located our displays right in the middle, with the books facing outward to that natural pathway. This needs to be continually emphasized in future redesign efforts. However, as frequently noted in the focus groups, the library's open atrium is one of our major architectural assets and we need to be careful to maintain its open and airy esthetic values and thereby preserve the benefits that it provides.

To increase library engagement, we also have to consider the sequential movement patterns of the visitors. A potential concern that emerged when we compared observational data to student focus group comments is whether some visitors only remain in the immediate first floor destinations because they are unaware of other resources or spaces that the library provides. The computer commons is overwhelmingly the most popular first destination for all library visitors and many students stop here, with no subsequent destinations. According to the student focus group comments, some students thought that the small first floor print reference collection constituted the entire library book collection and remarkably, several students in the focus groups had never been to the second or third floors of the library. 
Keywords: Pedestrian Choice, Academic Library, Engagement. p17

After the first stop, visitors disperse more broadly throughout the first floor of the library in subsequent stops. For example, we can see from Illustration \#2, that in all subsequent stops (stops 2-8), visits to the current periodicals shelves and new books cart show a greater proportion of visitors. We recognize that many students want to initially login to a computer when they enter the library (perhaps to check their email, Facebook account, or look up a book in the catalog).We need to consider how to better lead these students beyond the computer commons. Future research needs to probe how this can be achieved, whether it can be resolved by better signage, increased marketing, or creating situations that lead visitors (through library events, popular destinations, etc) to other areas of the library.

In fact, it was the small subgroup of visitors with four or more stops that engaged in the bulk of browsing or reading activities. For those visitors who made four or more stops, we defined four categories of visitors based on the characteristics of their stops and activities, as well as observer notes. Displayed on a grid, we characterized library visitors as Unsocial to Social on the X-axis and as having Purpose to No Purpose on the Y-axis. While all of these visitors crossed the spectrum of social to unsocial behavior, they differed in the immediacy of their library purpose. The first category were the driven visitors; these individuals were unsocial, with a clearly defined purpose for being in the library (such as returning a book, printing, getting a study room key, etc), and they efficiently went about their business. The second group of unsocial visitors were nesting; they obviously planned on an extended stay at the library and made themselves comfortable by moving tables and chairs, gathering materials (such as books, magazines, newspapers, or a laptop), or purchasing items from the vending machine before they finally 
settled down to work. Individuals within the third category were waiting; they wandered or browsed, chatted on a cell phone or texted until they met up with others and together as a group would move on. The individuals in the fourth group were browsing and seemed to lack a definitive goal; these visitors took their time looking at the displays, the new books, recreational reading, current periodicals, or media collections. Thus, these visitors with four or more stops represent an important subset of library visitors for understanding movement within the library space.

\section{Insert Illustration 3: Visitors with 4 or more stops.}

It should be noted that the circulation desk receives a far greater number of stops than the reference desk. The circulation desk is closer in location to both the library entrance and exit; while the reference desk is in close proximity to the computer commons. Future renovations should assess this spatial arrangement to potentially accommodate future growth of the computer commons, to determine whether separate service desks are still needed, and to explore what physical arrangement best directs general questions to the staff at the circulation desk, but more detailed questions to reference librarians.

Another distinct subgroup of library visitors were the $10 \%$ of visitors who went directly upstairs and did not engage in any leftward or rightward turns. Public spaces located on the library's second and third floors hold the circulating collection, study carrels, work tables, and private study rooms. While both the second and third floors are generally quiet, the third floor of the library is officially designated and marketed as the library's "Quiet Area." Thus, most visitors 
Keywords: Pedestrian Choice, Academic Library, Engagement. p19

who go to these areas know what they want -generally either a book or a location to escape the noise of other areas in the library or on campus. We also observed several students who went to the more remote areas of the first floor, where they would move the furniture around to create secluded nooks to study in greater privacy. The use of these remote tables, study carrels, and comfortable chairs can be seen in Illustration \#2. As the first stop location, many of these remote study locations received only five to nine total stops across all the observation cycles, increasing to 10-24 total stops for all subsequent stops, across all observations. In focus group discussions, several students mentioned that they liked finding the quiet little areas of the library where they could escape from noise and social interactions in order to focus on their studies. Thus, these quiet nooks where students can escape from more public social, noisy, and distracting spaces are also valuable destinations that libraries must consider in their design plans.

\section{Conclusions:}

This study has already begun to influence how we can better situate library resources and services and has generated low budget incremental redesign projects that meet the academic and social needs of the students, faculty, and university. A strategy we implemented to deal with space that is not directly along the natural pathways was to design desirable destinations that students want to visit. Following the three observation periods, our library redesigned a presentation area in the southwest corner of the 1st floor. This area was located farthest from the library entrance, and was further isolated by tall print periodical shelves that blocked the view and wireless signal. Observation data revealed that this was an underutilized area, but it had a beautiful view, with large windows on three sides overlooking the water, a marina, a park, and the Salvador Dali museum. Through the weeding of the print periodical collection, we removed 
three ranges of print periodical shelving, enlarging the usable space in this area. Our redesign emphasized flexibility by adding tables that could be easily moved to make larger tables, or moved apart for more intimate arrangements; a number of chairs on wheels, and a mobile white board. To meet the students expressed need for a collaborative work space that could be used to create and practice presentations, a computer with a widescreen TV as the computer screen was also added.

Thus, through the redesign, we aimed to increase the value of the area by highlighting the beautiful view and natural lighting, giving students the ability to control their spatial arrangement with adjustable furniture, and providing a large screen TV connected to a computer that was not available elsewhere on the campus. To increase awareness of the area, since students would never naturally walk back there, we developed several marketing strategies. We held a series of events in the area, including a science café lecture on evolution and an exhibit, demonstration, and faculty presentation on Mayan weaving. The availability of this new area was announced to all teaching faculty to encourage their students to work there on their class projects; we publicized the new presentation corner in the campus events calendar and the campus enewsletter; and finally, reference librarians led groups of students back to the new area when they asked about the best quiet place to work on projects.

Frequent assessment is needed to further refine our library space and continually adapt to future changes in our library's resources and services. Visitor movement research provides a set of tools for guiding this process. Known future changes on the short term horizon include continued weeding of the print periodical collection and the microfiche collection. Over a longer 
period, additional weeding of the media collection and print reference collection will also occur. All of these changes will open up space on our first floor where we need to consider how to best remodel our space to meet the changing needs of the students and faculty. The goal of encouraging greater faculty and student use and interaction with library services and resources needs to be at the forefront of all library design planning. This can be achieved by understanding how library visitors utilize their space, prioritizing popular services and resources by locating them close to the immediate vicinity of the library entrance, locating library displays along the natural pathway of students, and creating landmark destinations that draw students to less immediate locations of the library.

\section{Bibliography}

1. Freeman, G. T. "The Library as Place: Changes in Learning Patterns, Collections, Technology, and Use.” In Smith, K. (Ed.) Library as Place: Rethinking Roles, Rethinking Space. Washington, DC, Council on Library and Information Resources, 2005.

2. Space. Washington, DC, Council on Library and Information Resources. Seaman, S. "The Library as Learning Environment: Space Planning in an Academic Library." Colorado Libraries, 32 no.1 (2006): 5-7.

3. Sannwald, W.W. Checklist of library building design considerations. Chicago: American Library Association, 1997.

4. Fraley, R. A., and Anderson, C. L. Library Space Planning: A How-To-Do-It Manual for Assessing, Allocating and Reorganizing Collections, Resources and Facilities. New York: Neal-Schuman, 1990. 
5. Bennett, S. Libraries Designed for Learning. Washington D.C., Council on Library and Information Resources, 2003.

6. Association of Research Libraries. LibQUAL: Charting Library Service Quality.\{Accessed 12 May 2009\}Available from http://www.libqual.org/

7. Shill, H. B., and Tonner, S. "Creating a Better Place; Physical Improvements in Academic Libraries, 1995-2002.” College \& Research Libraries, 64 (2003): 431-466.

8. Shill, H. B., and Tonner, S. "Does the Building Still Matter? Usage Patterns in New, Expanded, and Renovated Libraries, 1995-2002." College \& Research Libraries, 65 no.2 (2004): 123-150.

9. Bennett, S. "The Choice for Learning." The Journal of Academic Librarianship 32 no. 1 (2006): 3-13.

10. McQuaid, H. L., Goel, A., and McManus, M. "When You Can't Talk to Customers: Using Storyboards and Narratives to Elicit Sympathy for Users.” DPPI '03: Proceedings of the 2003 International Conference on Designing Pleasurable Products and Interfaces, Pittsburgh, Pennsylvania, 2003.

11. Yates, J. C. Carnegie Library Putting Customers First. MSNBC.COM, Oct . 7, 2004, 2004, Sec. U.S. News, 2004. Available from http://www.msnbc.msn.com/id/6199275/.

12. Dempsey, B. "Library Buildings 2005: Power Users: Designing Buildings and Services from the End User's Viewpoint Transforms Access for Everyone. Library Journal \{online \}, 12/15/2005 \{cited 12 May 2009\}. Available from http://www.libraryjournal.com/article/CA6289901.html 
13. Coletta, C. Old habits and new realities, ed. Mickey McManus. Radio Interview.

Memphis, Tenn.: Smart City Radio, 2006. Available from

http://www.smartcityradio.com/smartcityradio/past_shows.cfm?showsmartcityID=298.

14. Given, L. M., and Leckie, G. J. "Sweeping" the Library: Mapping the Social Activity Space of the Public Library." Library \& Information Science Research, 25 (2003): 365385.

15. Foster, N. F., and Gibbons, S. (Eds.). Studying Students: The Undergraduate Research Project at the University of Rochester. Chicago: Association of College and Research Libraries, 2007.

16. Smithsonian Institution. Office of Policy and Analysis. \{Accessed 12 May 2009\} Washington D.C., Institutional Studies Office, 1999. Available from http://www.si.edu/opanda/index.html

17. Smithsonian Institution, Institutional Studies. Summer Visitors to "The Janet Annenberg Hooker Hall of Geology, Gems and Minerals" at the National Museum of Natural History. Washington D.C., Institutional Studies Office, 1999. \{ cited 12 May 2009\} Available from http://www.si.edu/opanda/Reports/Earlier/99-1$\underline{\text { SummerVisitors.pdf }}$

18. Smithsonian Institution, Institutional Studies. Examining Mammals: Three Studies of Visitor Responses to the Mammals Hall in the National Museum of Natural History. Washington D.C., Institutional Studies Office, 1999. \{cited 12 May 2009\} Available from http://www.si.edu/opanda/Reports/Earlier/99-5-Mammals.pdf

19. Bitgood, S. "An Analysis of Visitor Circulation: Movement Patterns and the General Value Principle." Curator 49 no.4 (2006): 463-475. 
20. Ibid.

21. Bitgood, S., and Dukes, S. "NOT ANOTHER STEP! Economy of Movement and Pedestrian Choice Point Behavior in Shopping Malls." Environment and Behavior 38 no.3 (2006): 394-405. 
Keywords: Pedestrian Choice, Academic Library, Engagement. p25

\section{Tables and Illustrations}

Illustration 1: Map and Tracking Guide for the Library's $1^{\text {st }}$ floor

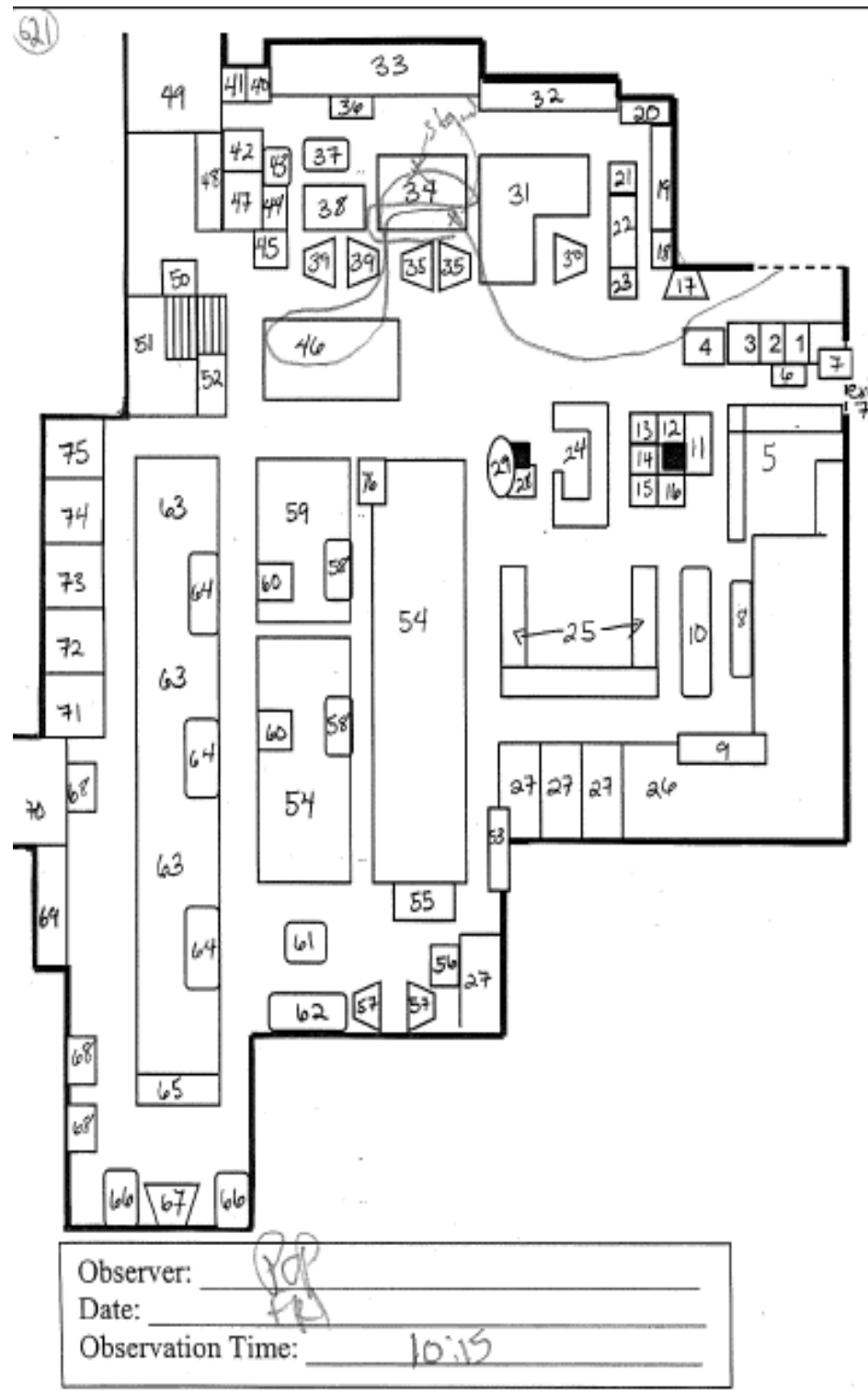

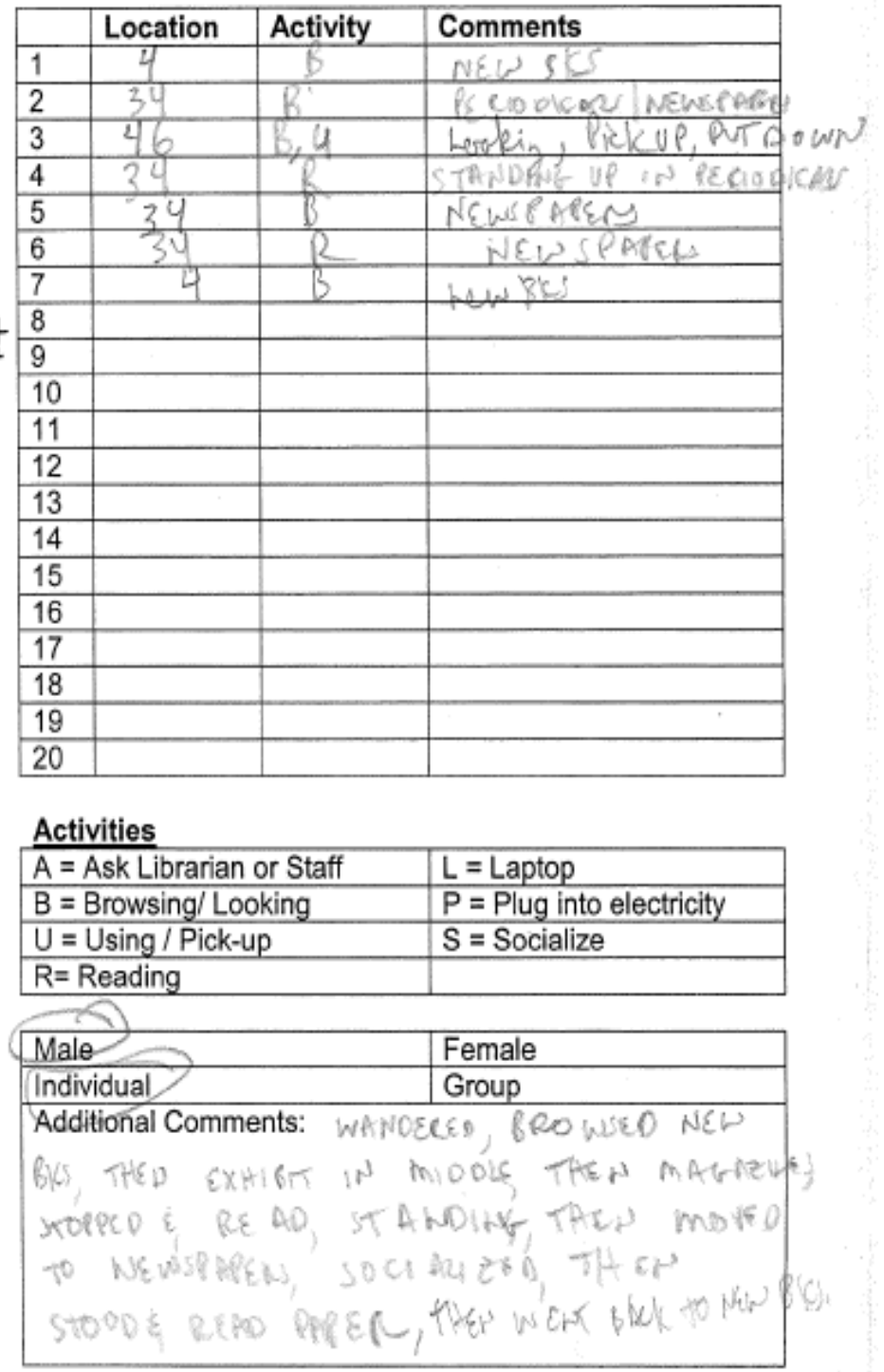




\section{Illustration 2: Circle Proportion Map of the Location and Number of Stops}

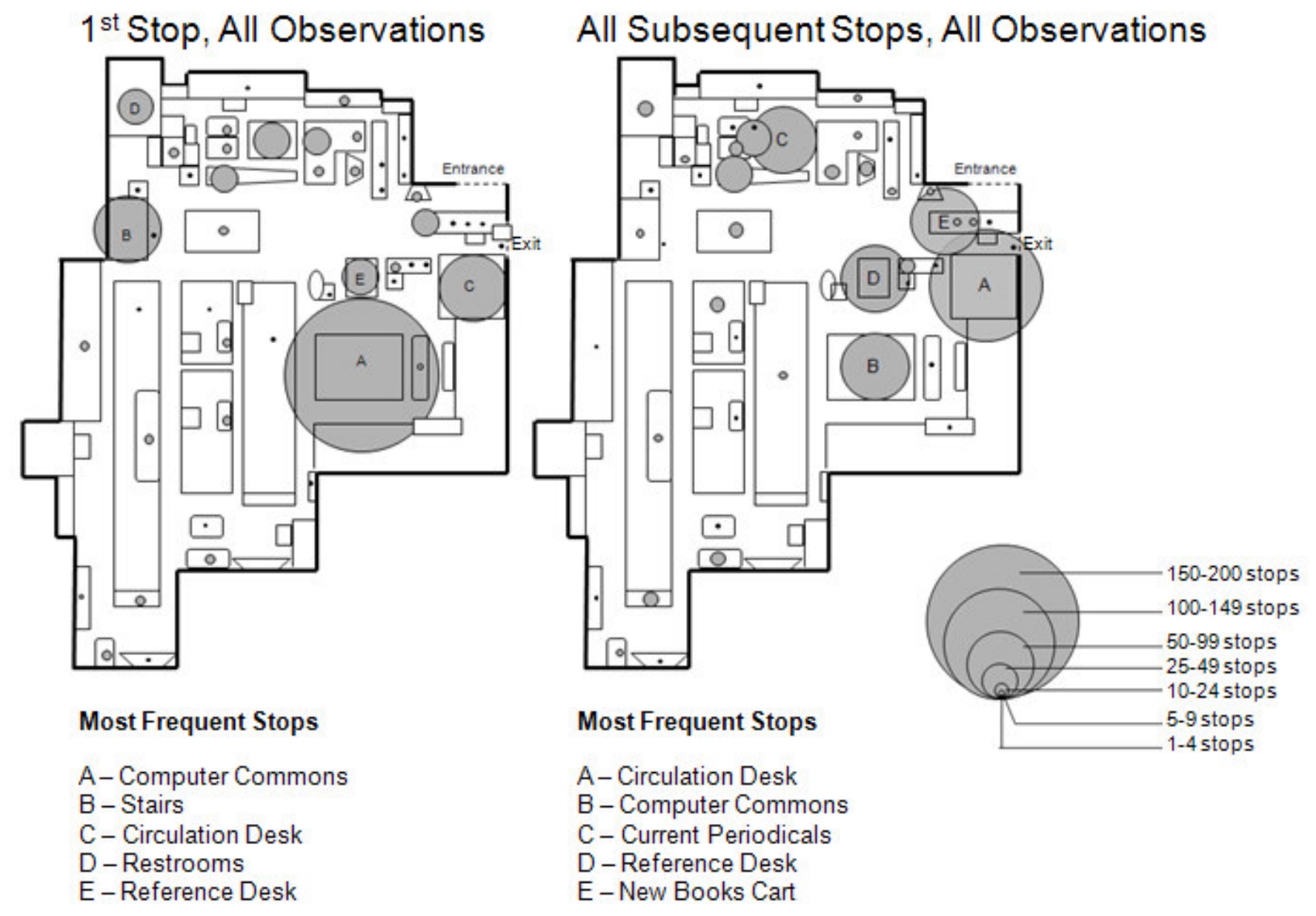


Keywords: Pedestrian Choice, Academic Library, Engagement. p27

Illustration \#3: Visitors with 4 or more stops.

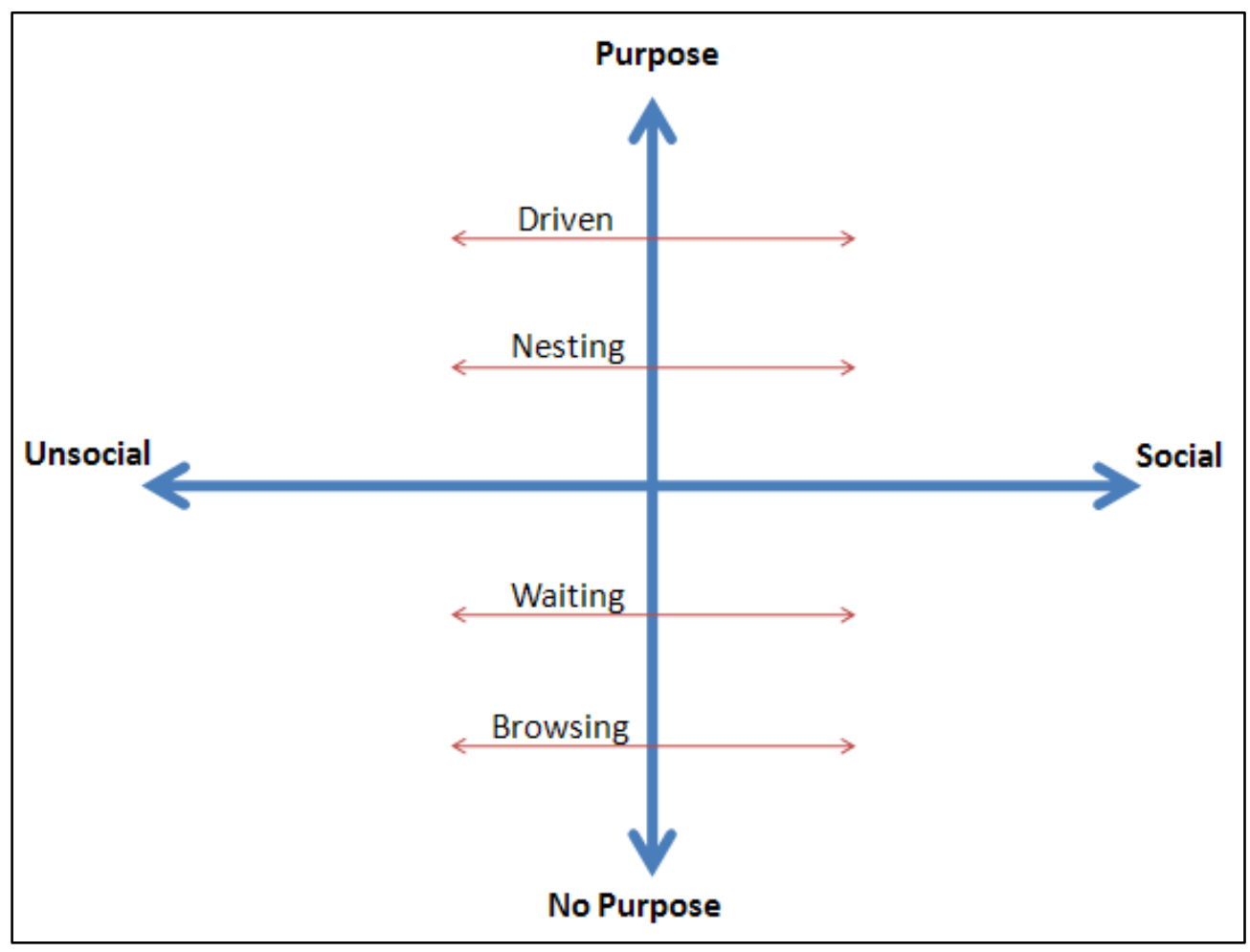

